\title{
MICROACESSIBILIDADE DE PEDESTRES NO ENTORNO DE ÁREAS ESCOLARES
}

\section{PEDESTRIANS' MICRO ACCESSIBILITY AROUND SCHOOL AREAS}

\author{
Bruna de Brito Prado ${ }^{1}$, Ms. \\ Renata Cardoso Magagnin², Dra \\ (1) Universidade Estadual Paulista "Julio de Mesquita Filho" (UNESP-PPGARQ) \\ e-mail: bruna@faac.unesp.br \\ (2) Universidade Estadual Paulista "Julio de Mesquita Filho" (UNESP-PPGARQ) \\ e-mail:magagnin@faac.unesp.br
}

Palavras-chave em português (Microacessibilidade, Pedestre, Áreas escolares)

\begin{abstract}
A existência de infraestrutura urbana adequada para a utilização dos modos de transporte mais sustentáveis no entorno de áreas escolares deve possibilitar conforto e segurança a todos os usuários. A possibilidade de avaliar e consequentemente adequar essas áreas, permitirá maior aderência ao uso desses modos de transporte. Os resultados mostram que o instrumento utilizado permite identificar quais são os melhores trajetos entre pontos de ônibus e escola, considerando os aspectos de conforto, segurança, seguridade, acessibilidade e sinalização.
\end{abstract}

Keywords in English (Micro accessibility, Pedestrian, School areas)

The existence of adequate urban infrastructure for the use of the most sustainable modes of transportation around school areas should allow for comfort and safety for all users. The possibility of evaluating and consequently adapting these areas will allow greater adherence to the use of these transportation modes. The results show the instrument used to identify the best routes between bus and school points, considering the aspects of comfort, safety, security, accessibility and signaling.

\section{Introdução}

O planejamento da mobilidade urbana contempla estratégias que possibilitam o movimento de pessoas e cargas nas áreas urbanas e rurais dos municípios [BRASIL, 2012; BRASIL, 2007a; BRASIL, 2007b; AGUIAR, 2010]. Acessibilidade, um dos aspectos para análise da mobilidade urbana, engloba a questão das barreiras em ambientes utilizados por pedestres, com ou sem algum tipo de deficiência ou restrição de mobilidade. Dentre os elementos mais relevantes para sua avaliação estão as calçadas e as travessias.

Considera-se, aqui, a infraestrutura do pedestre como a malha de calçadas e travessias das cidades. A qualidade da infraestrutura destinada ao pedestre facilita a mobilidade das pessoas para que exerçam suas atividades cotidianas.

Dentro do contexto da mobilidade urbana, a microacessibilidade está diretamente relacionada à análise do trajeto utilizado pelos pedestres. De 


\section{$16^{\circ}$ \\ ERGODESIGN USIHC CINAHPA}

$16^{\circ}$ Ergodesign - Congresso Internacional de Ergonomia e Usabilidade de Interfaces Humano Tecnológica: Produto, Informações Ambientes Construídos e Transporte

$16^{\circ}$ USIHC - Congresso Internacional de Ergonomia e Usabilidade de Interfaces Humano Computador

CINAHPA | 2017 - Congresso Internacional de Ambientes Hipermídia para Aprendizagem. acordo com Vasconcellos [2012, p.42] "a microacessibilidade mede o que acontece quando a pessoa chega perto do destino desejado, sem ainda ter chegado a ele". Litman [2008] complementa esta afirmação dizendo que a microacessibilidade pode ser afetada pela qualidade das condições físicas dos pedestres, pela proximidade e agrupamento de atividades e, pela infraestrutura viária ofertada. Neste artigo, este conceito foi adotado para avaliar o deslocamento do usuário (adolescente) entre um ponto de ônibus e a escola.

Nos últimos anos, muitas pesquisas tem enfocado as escolhas ou a tomada de decisão dos usuários em relação à escolha de modos de transportes [VAN EGGERMOND e ERATH, 2013]. No caso da escola, se o aluno escolher o deslocamento a pé para realizar sua viagem (seja através de um percurso completo ou complementar) é necessário escolher um trajeto dentre as opções existentes em uma rede de pedestres. O cálculo das distâncias de caminhada em uma rede de pedestres é diferente de uma rede de roteamento tradicional para o transporte privado, pois os pedestres são livres para se movimentarem no espaço urbano [VAN EGGERMOND e ERATH, 2013].

Na rede destinada aos pedestres, os indivíduos têm diferentes possibilidades para atravessar uma via e acessar uma calçada; no entanto, muitas vezes a própria calçada pode estar comprometida por impedimentos físicos que dificultam, em maior ou menor grau, sua passagem. Somado a este fator, alguns grupos de pessoas podem não estar habilitadas a utilizar todos os elementos (ou a infraestrutura física) de uma rede; em função de suas limitações de movimento, como por exemplo, os pais com carrinho de bebê ou usuários de cadeira de rodas ou deficientes visuais [VAN EGGERMOND e ERATH, 2013].

Silveira [2012] afirma que um espaço deve ser pensado para atender as mais variadas limitações físicas, permitindo, além de sua utilização pela pessoa com deficiência, o uso mais fácil e confortável para todos os outros usuários. No entanto, ao se observar o espaço destinado ao pedestre pode-se verificar inúmeros impedimentos ou obstáculos físicos.

Bianchi [2011] relata que as rotas de pedestres são normalmente configuradas como espaços remanescentes do sistema de circulação motorizado; são caracterizadas por sua descontinuidade, pela presença de barreiras físicas e por serem compostas de distâncias maiores devido à priorização dada ao sistema de transporte motorizado.

De acordo com Asadi-Shekari, Moeinaddini e Shah [2015] vários fatores podem comprometer a segurança dos pedestres em uma rota: fatores relacionados ao tráfego, às condições do ambiente e ao próprio indivíduo. Este último, é o que mais se destaca, pois os indivíduos como: crianças, idosos e pessoas com deficiência são considerados utilizadores vulneráveis ao tráfego.

Em áreas escolares (raio de aproximadamente 500m da escola), a importância da microacessibilidade é maior devido às dificuldades que adolescentes tem em lidar com o tráfego por terem pouca experiência com o ambiente urbano; por serem vulneráveis à acidentes, devido à falta de atenção; pela baixa estatura e pela dificuldade em julgar a velocidade real dos veículos [IPINGBEMI; AIWORO, 2013].

É necessário enfatizar que as viagens dos adolescentes para a escola são realizadas em horários de pico e que acontecem diversos deslocamentos, de diversas pessoas, de diferentes regiões das cidades ao mesmo tempo, o que aumenta a probabilidade de acidentes caso a infraestrutura não contribua para o conforto e segurança do usuário. Dentre as possíveis consequências desses acidentes destacam-se: arranhões, luxações, hematomas, fraturas, além de questões relacionadas às ordens emocionais e psicológicas.

Para permitir que os adolescentes tenham independência no deslocamento até a escola é necessário promover infraestrutura adequada e segura no entorno das áreas escolares e; para que essa infraestrutura seja implementada de modo
Realização:
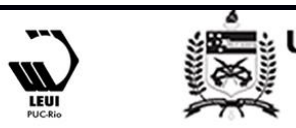


\section{$16^{\circ}$ \\ ERGODESIGN USIHC CINAHPA}

$16^{\circ}$ Ergodesign - Congresso Internacional de Ergonomia e Usabilidade de Interfaces Humano Tecnológica: Produto, Informações Ambientes Construídos e Transporte

$16^{\circ}$ USIHC - Congresso Internacional de Ergonomia e Usabilidade de Interfaces Humano Computador

CINAHPA | 2017 - Congresso Internacional de Ambientes Hipermídia para Aprendizagem. eficaz faz-se necessário que especialistas das áreas de planejamento urbano e mobilidade urbana tenham instrumentos ou ferramentas que facilitem a realização de um diagnóstico desses locais para propor as intervenções necessárias nessas áreas.

Pesquisadores brasileiros e do exterior avaliaram o ambiente do pedestre utilizando indicadores e índices para realizar diagnósticos da qualidade da infraestrutura do pedestre. Essas pesquisas tiveram por finalidade: avaliar a segurança e o conforto de calçadas e lugares de uso públicos por meio da definição do grau de mobilidade, acessibilidade, caminhabilidade desses ambientes; bem como da proposição de rotas mínimas acessíveis. O públicoalvo da maioria destas pesquisas foi o usuário de cadeira de rodas e as pessoas com deficiência motora. No entanto, não foram analisados, de forma conjunta, os aspectos da microacessibilidade relacionados à segurança, à seguridade, ao conforto e à sinalização no entorno de áreas escolares.

Diante do exposto, este artigo apresenta o resultado da aplicação de uma proposta metodológica para mensurar a microacessibilidade no entorno escolar por meio de indicadores. Este instrumento permite identificar quais são os melhores trajetos entre pontos de ônibus e escola, considerando os aspectos de conforto, segurança, seguridade, acessibilidade e sinalização.

\section{Objeto de Estudo}

O estudo de caso foi realizado entre os anos de 2015 e 2016, no município de Bauru, localizado na região centro-oeste do Estado de São Paulo. O recorte espacial definido para análise está localizado no entorno da Escola Estadual (EE) Dr. Luiz Zuiani (denominada de Escola I), implantada na região leste da cidade de Bauru, próxima a duas importantes vias arteriais do município: Avenida Duque de Caxias e Avenida Cruzeiro do Sul, ver figura 1.

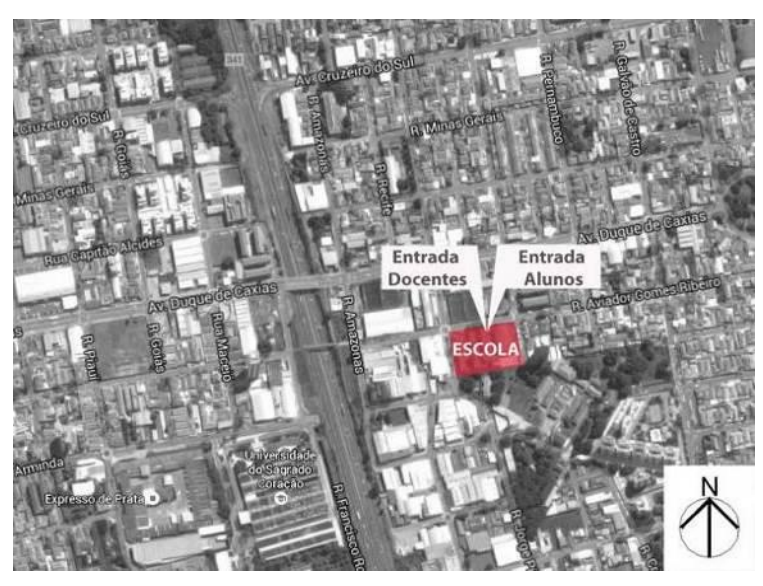

Figura 1 - Localização da Escola I no entorno escolar. Fonte: (a) Adaptado do Google Maps, 2016.

O entorno escolar desta região é caracterizado por apresentar malha ortogonal (figura 1), com uso do solo misto. A caracterização da malha urbana no entorno dessa escola é de quadras quadradas de 104,30 metros por 104,30 metros, com malha regular, entretanto existem algumas quadras desmembradas em duas e outras até em quatro partes.

O sistema viário é composto por uma via estrutural (Avenida Duque de Caxias) com alto fluxo de veículos que possibilita o percurso bairro-centro da cidade e por vias coletoras que possuem um fluxo médio de veículos próximo à via arterial. As travessias da avenida e de ruas perpendiculares a ela normalmente são semaforizadas, sendo que algumas outras travessias apresentam canaletas ou lombadas para diminuição de velocidade dos veículos.

A infraestrutura destinada ao pedestre nesta região é regular. As calçadas medem em média de 1,50 a 2,50 metros de largura, na maior parte da área a manutenção é boa. Sobre as áreas dos pontos de ônibus, em sua maioria apresentam-se dentro da faixa livre de circulação do pedestre, comportandose como obstrução permanente da calçada; alguns pontos apresentam cobertura, consequentemente também apresentam bancos, informações das linhas; entretanto, quando o tipo do ponto de ônibus não contempla a cobertura não existe bancos, nem informações. 


\section{$16^{\circ}$ \\ ERGODESIGN USIHC CINAHPA}

A escola está implantada numa área com declividade regular, o que pode interferir diretamente na acessibilidade e na escolha das opções de rotas existentes para chegar até a escola.

\section{Instrumentos Metodológicos}

A metodologia utilizada para avaliar a microacessibilidade no entorno escolar foi composta pelas etapas abaixo discriminadas.

Definição da área de abrangência do entorno escolar - a primeira etapa consistiu na definição do entorno escolar a ser analisado. Este raio foi definido com base na definição da distância Euclidiana - distância ideal máxima utilizada para análise de trajetos de pedestres. Rodrigues; Sorratini [2008] e Pianucci [2011] demonstraram em suas pesquisas que a distância mais confortável para um pedestre percorrer entre o início e fim de um percurso (ex. casa-ponto de ônibus) é de 500m, distâncias maiores não são confortáveis (figura 2).

Identificação dos pontos de ônibus - nesta etapa foi realizada a análise da distribuição de todas as linhas que passavam por cada ponto de ônibus dentro da área de abrangência da escola. Foram selecionados os pontos de ônibus mais próximos à escola, para cada linha, considerando o trajeto de ida e volta de todas as linhas que alimentam a região da escola, conforme figura 2 .

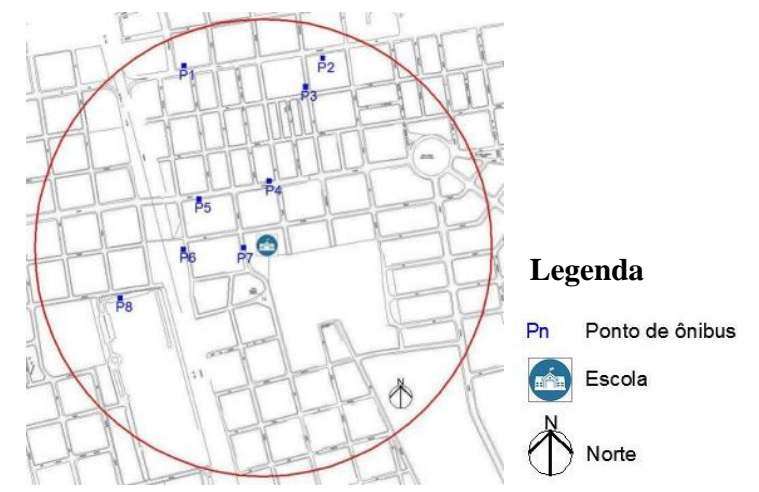

Figura 2 - Exemplo de recorte espacial, com a localização dos pontos de ônibus, sem escala. Fonte: Prado, 2016.

Identificação dos tipos de faces de quadra - $16^{\circ}$ Ergodesign - Congresso Internacional de Ergonomia e Usabilidade de Interfaces Humano Tecnológica: Produto, Informações Ambientes Construídos e Transporte

$16^{\circ}$ USIHC - Congresso Internacional de Ergonomia e Usabilidade de Interfaces Humano Computador

CINAHPA | 2017 - Congresso Internacional de Ambientes Hipermídia para Aprendizagem.

Após a definição dos pontos de ônibus foram identificados todos os tipos de faces de quadra presentes no entorno escolar estudado. Para esta análise, considerou-se a face de quadra como a composição de "um trecho de calçada e sua intersecção (travessia) seguinte" [NANYA; SANCHES, 2015, p 1705].

A figura 3 apresenta a identificação dos 8 tipos de faces de quadras encontradas neste recorte espacial.

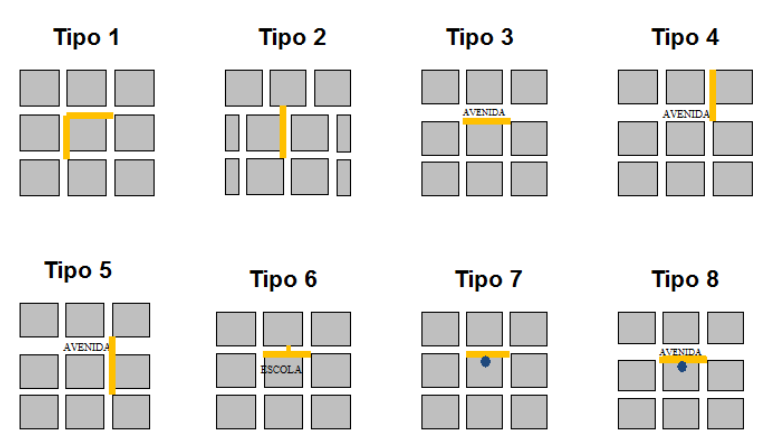

Figura 3 - Tipos de faces de quadras

A área é composta por 8 tipos de faces de quadras distribuídas em 111 faces de quadra analisadas (figura 4).

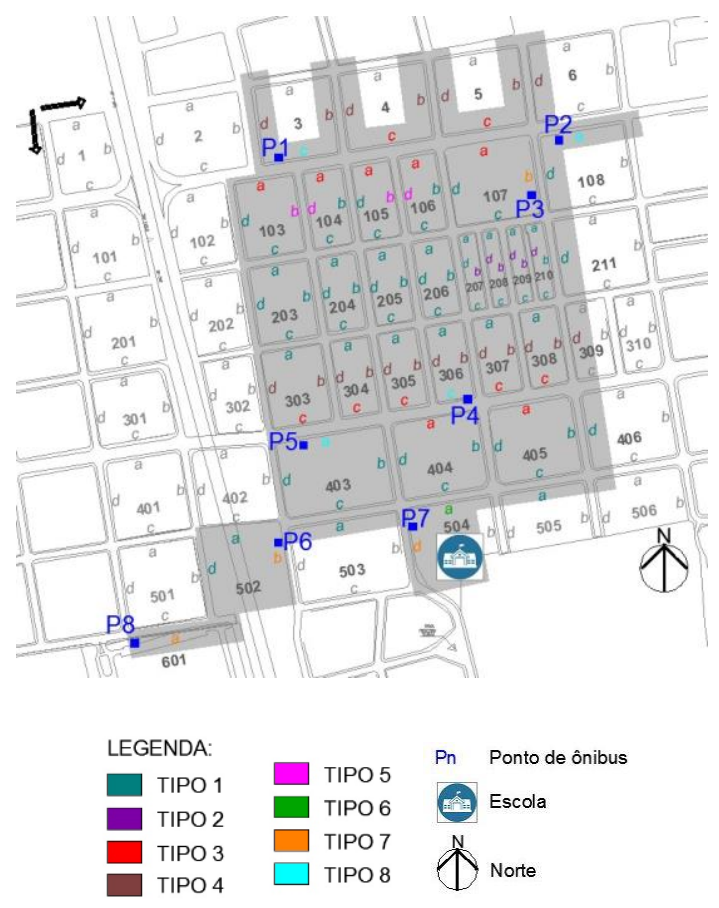

Realização:

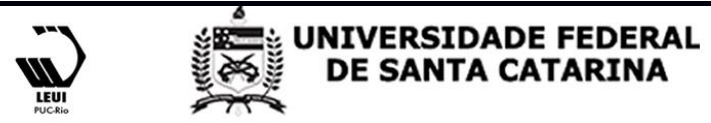




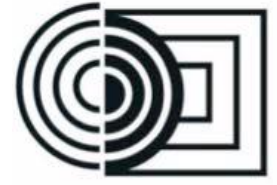
CINAHPA

Figura 4 - Definição dos tipos de faces de quadras da Escola, sem escala.

Definição dos Temas e Indicadores - O sistema proposto é composto por 3 Domínios, 6 Temas e 27 Indicadores (tabela 1) que permitem avaliar o grau da microacessibilidade no entorno escolar.

\begin{tabular}{|c|c|c|}
\hline DOM & TEMA & INDICADOR \\
\hline \multirow{11}{*}{ 岕 } & \multirow{10}{*}{$\begin{array}{l}\text { Acessibilidade } \\
\text { (Barreiras } \\
\text { Físicas) }\end{array}$} & Largura efetiva $-\mathrm{C}_{\mathrm{ACS} 1}$ \\
\hline & & Tipo de piso - $\mathrm{C}_{\mathrm{ACS} 2}$ \\
\hline & & $\begin{array}{l}\text { Estado de conservação da superfície do piso } \\
-\mathrm{C}_{\mathrm{ACS} 3}\end{array}$ \\
\hline & & Inclinação longitudinal - $\mathrm{C}_{\mathrm{ACS} 4}$ \\
\hline & & Inclinação transversal - $\mathrm{C}_{\mathrm{ACS} 5}$ \\
\hline & & Desnível - $\mathrm{C}_{\mathrm{ACS} 6}$ \\
\hline & & Altura livre - $\mathrm{C}_{\mathrm{ACS} 7}$ \\
\hline & & Obstrução temporária - $\mathrm{C}_{\mathrm{ACS} 8}$ \\
\hline & & Obstrução permanente - $\mathrm{C}_{\mathrm{ACS} 9}$ \\
\hline & & Grelha - $\mathrm{C}_{\mathrm{ACS} 10}$ \\
\hline & Seguridade & Iluminação - $\mathrm{C}_{\mathrm{SGD} 1}$ \\
\hline \multirow{9}{*}{ 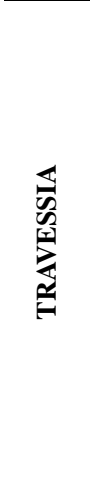 } & \multirow{9}{*}{ Segurança } & Sinalização de faixas de pedestres - $\mathrm{T}_{\mathrm{SGN} 1}$ \\
\hline & & Sinalização vertical de travessia - $\mathrm{T}_{\mathrm{SGN} 2}$ \\
\hline & & Rebaixamento de guia - $\mathrm{T}_{\mathrm{SGN} 3}$ \\
\hline & & Visão de aproximação dos veículos - $\mathrm{T}_{\mathrm{SGN} 4}$ \\
\hline & & Redutor de velocidade -- $\mathrm{T}_{\mathrm{SGN} 5}$ \\
\hline & & Sinalização horizontal ESCOLA - $\mathrm{T}_{\mathrm{SGN} 6}$ \\
\hline & & $\begin{array}{l}\text { Sinalização vertical de proximidade de } \\
\text { escola - } T_{\mathrm{SGN} 7}\end{array}$ \\
\hline & & $\begin{array}{l}\text { Sinalização vertical de velocidade máxima } \\
\text { de veículos - } \mathrm{T}_{\mathrm{SGN} 8}\end{array}$ \\
\hline & & Operação de trânsito - $\mathrm{T}_{\mathrm{SGN} 9}$ \\
\hline \multirow{7}{*}{ 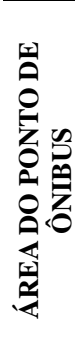 } & \multirow{3}{*}{ Conforto } & Cobertura - $\mathrm{P}_{\text {CFT1 }}$ \\
\hline & & Banco - $\mathrm{P}_{\mathrm{CFT2}}$ \\
\hline & & Informações - $\mathrm{P}_{\text {CFT3 }}$ \\
\hline & \multirow{2}{*}{ Acessibilidade } & Espaço para cadeira de rodas - $\mathrm{P}_{\mathrm{ACS} 1}$ \\
\hline & & Sinalização tátil - $\mathrm{P}_{\mathrm{ACS} 2}$ \\
\hline & \multirow[t]{2}{*}{ Segurança } & $\begin{array}{l}\text { Localização no comprimento da calçada - } \\
\text { P }_{\mathrm{SGN} 1}\end{array}$ \\
\hline & & Localização na largura da calçada - $\mathrm{P}_{\mathrm{SGN} 2}$ \\
\hline & \multicolumn{2}{|c|}{$\begin{array}{c}\text { Tabela } 1 \text { - Estrutura hierárquica dos Temas e } \\
\text { Indicadores } \\
\text { Fonte: Prado, } 2016 .\end{array}$} \\
\hline
\end{tabular}

De acordo com Prado [2016] a definição do sistema teve como referência os trabalhos dos seguintes pesquisadores: Ferreira; Sanches [2007]; $16^{\circ}$ Ergodesign - Congresso Internacional de Ergonomia e Usabilidade de Interfaces Humano Tecnológica: Produto, Informações Ambientes Construídos e Transporte

$16^{\circ}$ USIHC - Congresso Internacional de Ergonomia e Usabilidade de Interfaces Humano Computador

CINAHPA | 2017 - Congresso Internacional de Ambientes Hipermídia para Aprendizagem.

Orlandi [2003]; Keppe Junior [2007]; Mitchell; Kearns; Collins [2007]; Dischinger; Bins Ely; Borges [2009]; Zaly Shah; Rodrigues da Silva [2010]; Campêlo [2011]; Magagnin; Fontes; Salcedo [2014]; Asadi-Shekari; Moeinaddini; Zaly Shah [2015]; Oliveira [2015]; Nanya; Sanches [2015; 2016] e Prado; Magagnin [2016].

A escala de avaliação, nota, para cada indicador é diferenciada de acordo com a situação encontrada in loco, correspondendo a um valor numérico dentro do intervalo de 0 a 1 , sendo 0 a pior avaliação e a 1 a melhor. A forma de avaliação pode ser vista por um modelo de um dos Domínios na tabela 2.

\begin{tabular}{|c|c|c|c|}
\hline IND & DEFINIÇÃO & FORMA DE ANÁLISE & NTS \\
\hline \multirow[t]{3}{*}{$\begin{array}{l}\text { Largura } \\
\text { efetiva }\end{array}$} & \multirow[t]{3}{*}{$\begin{array}{l}\text { Largura disponível } \\
\text { para circulação de } \\
\text { pedestre na } \\
\text { calçada. }\end{array}$} & $\begin{array}{l}\text { Largura da faixa livre de } \\
\text { algum lote da face de quadra } \\
\text { é menor do que } 1,20 \mathrm{~m} \text { ou } \\
\text { ausência de faixa livre. }\end{array}$ & 0,0 \\
\hline & & $\begin{array}{l}\text { Largura da faixa livre de } \\
\text { todos os lotes da face de } \\
\text { quadra entre } 1,20 \mathrm{~m} \text { e } 1,50 .\end{array}$ & 0,5 \\
\hline & & $\begin{array}{l}\text { Largura da faixa livre de } \\
\text { todos os lotes da face de } \\
\text { quadra acima de } 1,50 \mathrm{~m} \\
\text { (mínimo). }\end{array}$ & 1,0 \\
\hline \multirow[t]{2}{*}{$\begin{array}{l}\text { Tipo de } \\
\text { piso }\end{array}$} & \multirow[t]{2}{*}{$\begin{array}{l}\text { Característica do } \\
\text { material de } \\
\text { revestimento do } \\
\text { piso da calçada } \\
\text { (escorregadio, } \\
\text { rugoso ou } \\
\text { trepidante). }\end{array}$} & $\begin{array}{l}\text { Presença de material liso } \\
\text { (piso cerâmico, } \\
\text { paralelepípedo, concreto } \\
\text { polido, pedras em geral) ou } \\
\text { com alto e baixo relevo que } \\
\text { provoque trepidação } \\
\text { (mosaico português, ladrilho } \\
\text { hidráulico, concreto } \\
\text { estampado) ou ausência de } \\
\text { pavimentação, ou com } \\
\text { faixas de grama em algum } \\
\text { lote da face de quadra. }\end{array}$ & 0,0 \\
\hline & & $\begin{array}{l}\text { Presença de material regular, } \\
\text { firme, antiderrapante e } \\
\text { antitrepidante (piso } \\
\text { cerâmico poroso, piso } \\
\text { intertravado, concreto bruto, } \\
\text { ladrilho hidráulico sem } \\
\text { relevo) em todos os lotes da } \\
\text { face da quadra. }\end{array}$ & 1,0 \\
\hline
\end{tabular}

Tabela 2 - Exemplo de critérios para avaliação dos indicadores relacionados ao Domínio Calçada, Tema Acessibilidade (Barreiras Físicas) Fonte: Prado, 2016.

Definição dos pesos de cada indicador - De 


\section{$16^{\circ}$ \\ ERGODESIGN USIHC CINAHPA}

acordo com a metodologia de Prado [2016], cada indicador recebe pesos distintos de acordo com a facilidade de sua adequação, ou seja, quanto mais difícil de alterar o indicador para que fique de acordo com as normas existentes, maior o valor do peso. Os pesos dos indicadores são definidos comparando-os todos entre si, assim como por Tema.

$\mathrm{O}$ método assume que cada peso encontra-se em um intervalo numérico de 0 a 1 . A somatória dos pesos dos indicadores de um mesmo tipo de face de quadra tem valor igual a 1 . O mesmo procedimento é adotado para o cálculo dos Temas de um tipo de face de quadra. Este procedimento foi realizado para cada tipo de face de quadra, em função da diferenciação de Indicadores e Temas presentes em cada uma delas.

A tabela 3 apresenta o modelo da distribuição dos pesos dos tipos de faces de quadra 1 e 2 .

\begin{tabular}{|c|c|c|c|}
\hline Dom & Tema & Indicador & $\begin{array}{c}\text { Peso } \\
\text { Parcial }\end{array}$ \\
\hline \multirow{11}{*}{ 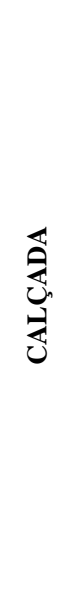 } & \multirow{10}{*}{$\begin{array}{l}\text { Acessibilidade } \\
\text { (Barreiras } \\
\text { Físicas) } \\
(P=0,800)\end{array}$} & Largura efetiva & 0,230 \\
\hline & & Tipo de piso & 0,070 \\
\hline & & $\begin{array}{l}\text { Estado de conservação da } \\
\text { superfície do piso }\end{array}$ & 0,040 \\
\hline & & Inclinação longitudinal & 0,100 \\
\hline & & Inclinação transversal & 0,100 \\
\hline & & Desnível & 0,100 \\
\hline & & Altura livre & 0,020 \\
\hline & & Obstrução temporária & 0,010 \\
\hline & & Obstrução permanente & 0,080 \\
\hline & & Grelha & 0,050 \\
\hline & $\begin{array}{l}\text { Seguridade } \\
(\mathrm{P}=0,060)\end{array}$ & Iluminação & 0,060 \\
\hline \multirow{4}{*}{ 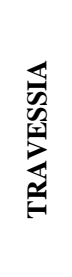 } & \multirow{4}{*}{$\begin{array}{l}\text { Segurança } \\
(P=0,140)\end{array}$} & $\begin{array}{l}\text { Sinalização de faixas de } \\
\text { pedestres }\end{array}$ & 0,020 \\
\hline & & Sinalização vertical de travessia & 0,040 \\
\hline & & Rebaixamento de guia & 0,050 \\
\hline & & $\begin{array}{l}\text { Visão de aproximação dos } \\
\text { veículos }\end{array}$ & 0,030 \\
\hline \multicolumn{2}{|c|}{ TOTAL $_{\text {TEMA }} \quad 1,000$} & TOTAL $_{\text {INDICADOR }}$ & 1,000 \\
\hline
\end{tabular}

Tabela 3 - Pesos dos Indicadores e Temas das faces de quadra de Tipo 1 e 2

Fonte: Prado, 2016. $16^{\circ}$ Ergodesign - Congresso Internacional de Ergonomia e Usabilidade de Interfaces Humano Tecnológica: Produto, Informações Ambientes Construídos e Transporte

$16^{\circ}$ USIHC - Congresso Internacional de Ergonomia e Usabilidade de Interfaces Humano Computador

CINAHPA | 2017 - Congresso Internacional de Ambientes Hipermídia para Aprendizagem.

\section{Calculo do Índice de Microacessibilidade do} Pedestre no entorno de áreas EScolares (IMPES) - esse índice é calculado em 7 etapas, com auxílio de formulário de auditoria técnica (checklist), nos quais são inseridos os dados coletados in loco, posteriormente, são realizados os seguintes procedimentos: i) cálculo dos indicadores; ii) ponderação dos comprimentos das faces de

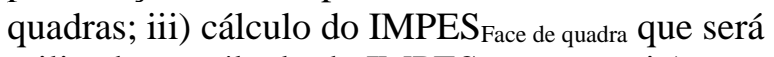
utilizado no cálculo do IMPES Tipo de quadra; $_{\text {;v) }}$

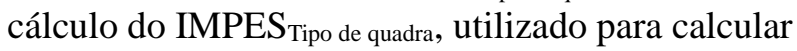
o índice por tipo, considerando o comprimento total (somatória) de todas as faces de quadra que compõem determinado tipo; v) cálculo do IMPES $_{\text {Global, }}$, a somatória dos IMPES Tipo de quadra; $_{\text {; }}$; vi) cálculo do IMPES Global Max $_{\text {, utilizado como }}$ referência para saber qual o valor máximo que o índice poderia atingir, caso a avaliação fosse a melhor possível; vii) cálculo do IMPES Ponderado por face de quadra, utiliza a ponderação do comprimentos das faces de quadra e das notas dos indicadores para definir o grau de microacessibilidade por face de quadra. Este índice permite avaliar o ambiente de pedestres de forma global (IMPES $S_{\text {Global }}$ e identificar as melhores rotas entre o trajeto ponto

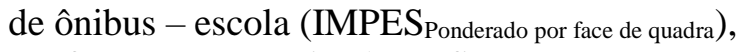
conforme esquematizado na figura 5 .

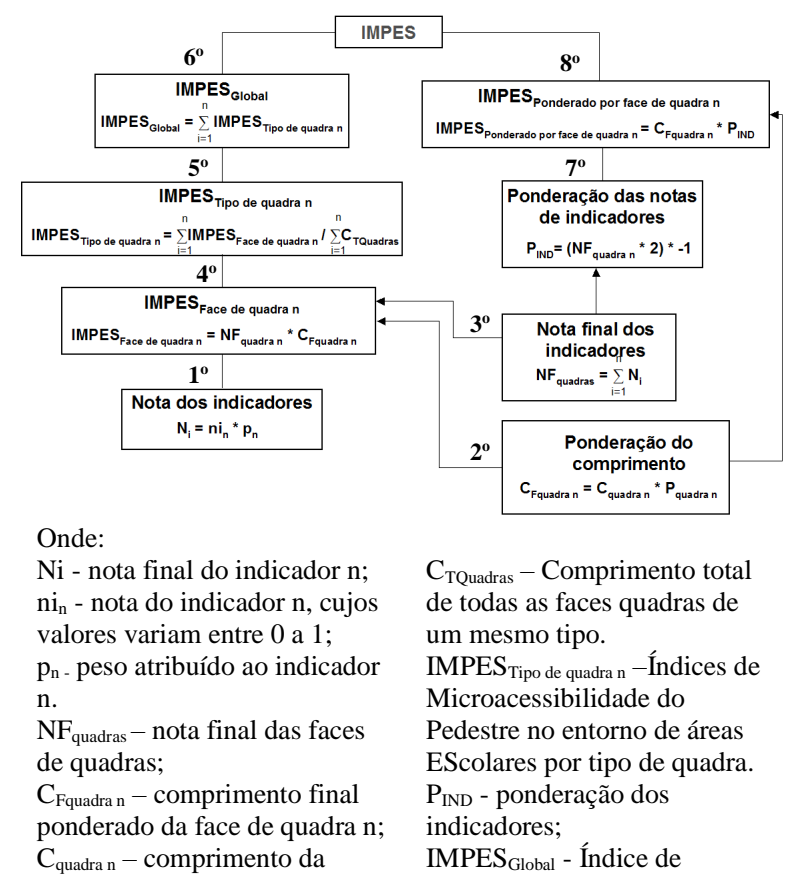

Realização: 


\section{$16^{\circ}$ \\ ERGODESIGN USIHC CINAHPA}

\begin{abstract}
Microacessibilidade do
Pedestre no entorno de áreas EScolares global;

IMPES ${ }_{\text {Ponderado por face de quadra n }}$ Índice de Microacessibilidade do Pedestre no entorno de áreas EScolares ponderado por face de quadra.
\end{abstract}

Figura 5 - Estrutura de avaliação do IMPES

O resultado de cada IMPES $S_{\text {Tipo de quadra é analisado }}$ utilizando a classificação da tabela 4.

\begin{tabular}{|c|c|}
\hline $\mathbf{0 , 8 1 - 1 , 0 0}$ & ÓTIMO \\
\hline $\mathbf{0 , 6 1 - 0 , 8 0}$ & BOM \\
\hline $\mathbf{0 , 4 1 - 0 , 6 0}$ & REGULAR \\
\hline $\mathbf{0 , 2 1 - 0 , 4 0}$ & RUIM \\
\hline $\mathbf{0 , 0 0 - 0 , 2 0}$ & PÉSSIMO \\
\hline
\end{tabular}

Tabela 4 - Classificação do IMPES Tipo de quadra

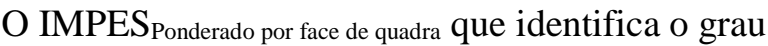
de microacessibilidade no entorno da unidade escolar deve ser analisado utilizando os dados da tabela 5.

\begin{tabular}{ccc}
\hline Escala & ÓTIMO & $\begin{array}{c}\text { Deslocamento Muito favorável } \\
\text { ao pedestre }\end{array}$ \\
\hline $100-61$ & BOM & $\begin{array}{c}\text { Deslocamento Favorável ao } \\
\text { pedestre }\end{array}$ \\
\hline 20 a $(-20)$ & REGULAR & $\begin{array}{c}\text { Deslocamento Parcialmente } \\
\text { favorável ao pedestre }\end{array}$ \\
\hline$(-21)$ a (-60) & RUIM & $\begin{array}{c}\text { Deslocamento Desfavorável } \\
\text { aos pedestres }\end{array}$ \\
\hline$(-61)$ a (-100) & PÉSSIMO & $\begin{array}{c}\text { Deslocamento Muito } \\
\text { desfavorável ao pedestre }\end{array}$ \\
\hline
\end{tabular}

Tabela 5 - Escala de avaliação do IMPES Ponderado por face de quadra

Fonte: Adaptado de Zaly Shah; Rodrigues da Silva, 2010.

\section{Resultados e Discussões}

A partir da realização da vistoria técnica no entorno escolar, os dados das 8 faces de quadras foram tabulados. A tabela 6 apresenta um exemplo da ponderação dos comprimentos de cada face de quadra, os valores do IMPES Face de quadra, a ponderação das notas finais dos indicadores e os valores do IMPES Ponderado de face de quadra. $16^{\circ}$ Ergodesign - Congresso Internacional de Ergonomia e Usabilidade de Interfaces Humano Tecnológica: Produto, Informações Ambientes Construídos e Transporte

$16^{\circ}$ USIHC - Congresso Internacional de Ergonomia e Usabilidade de Interfaces Humano Computador

CINAHPA | 2017 - Congresso Internacional de Ambientes Hipermídia para Aprendizagem.

\begin{tabular}{|c|c|c|c|c|}
\hline \multirow[b]{2}{*}{ Cálculos } & \multicolumn{4}{|c|}{ Face de Quadra } \\
\hline & $103 b$ & $104 d$ & $105 b$ & $106 d$ \\
\hline $\begin{array}{l}\text { SOMA da } \\
\text { normalização dos } \\
\text { indicadores (Nota do } \\
\text { indicador } x \text { peso do } \\
\text { indicador) } \\
\end{array}$ & 0,261 & 0,376 & 0,24 & 0,301 \\
\hline $\begin{array}{l}\text { Comprimento da face } \\
\text { de quadra }\end{array}$ & 114,32 & 114,38 & 114,32 & 113,38 \\
\hline $\begin{array}{l}\text { Peso segmento face } \\
\text { de quadra }\end{array}$ & 1 & 1 & 1 & 1 \\
\hline $\begin{array}{l}\text { CF Quadra n } \\
\text { (comprimento } x \text { peso } \\
\text { do segmento) }\end{array}$ & 114,32 & 114,38 & 114,32 & 113,38 \\
\hline $\begin{array}{l}\text { IMPES face de } \\
\text { quadra n (Nf x CF) }\end{array}$ & 29,84 & 43,01 & 27,44 & 34,07 \\
\hline $\begin{array}{l}P_{\text {IND padronização da }} \\
\text { soma dos ind. } \\
\text { segmento }\end{array}$ & $-0,478$ & $-0,248$ & $-0,52$ & $-0,399$ \\
\hline $\begin{array}{l}\text { IMPES ponderado de } \\
\text { face de quadra }\left(P_{\text {IND }}\right. \\
x \text { CFponderado) }\end{array}$ & $-54,64$ & $-28,37$ & $-59,45$ & $-45,24$ \\
\hline \multicolumn{5}{|c|}{ IMPES $_{\text {Tipo 5 }}=0,294$ RUIM } \\
\hline
\end{tabular}

O entorno da Escola apresenta calçadas com largura adequada, em sua maioria, e poucos locais com obstrução permanente. A inclinação transversal no geral é adequada e foi identificada a presença de poucas grelhas irregulares. Constatouse alguns problemas em relação à presença de degraus acima da altura recomendada pela NBR 9050. Em relação ao tipo de piso, diversos locais apresentam piso escorregadio e trepidante. A área da escola é bem sinalizada com o mínimo recomendado de sinalização de proximidade de escola e de velocidade de veículos.

A maior parte das travessias não apresenta rebaixamento de guia. As calçadas demonstram falta de manutenção, em sua maioria, melhorando apenas na avenida. Os pontos de ônibus não apresentam demarcação com sinalização tátil. Há faixas de pedestres junto às travessias da avenida, no entanto, nas demais travessias elas não existem em todos os cruzamentos ou estão apagadas. 


\section{$16^{\circ}$ \\ ERGODESIGN USIHC CINAHPA}

Operação de trânsito com guarda de trânsito é inexistente na proximidade da escola.

Em relação à análise dos indicadores associados ao Tema Área do ponto de ônibus, verificou-se ausência dos seguintes elementos: informações sobre as linhas de ônibus, horários, bancos e espaço para cadeira de rodas. Acerca da presença de cobertura nos pontos de ônibus, 5 dos 8 pontos de ônibus analisados apresentam cobertura. A iluminação, em sua maior parte, é deficiente na área analisada.

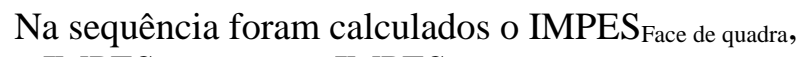
o IMPES $S_{\text {Tipo de quadra }}$ IMPES Global.. $_{\text {. }}$

Para identificar o grau de microacessibilidade do pedestre encontrado no entorno da Escola I foi calculado o IMPES ${ }_{\text {Tipo de quadra; }}$ o cálculo deste índice corresponde à divisão da somatória de todos

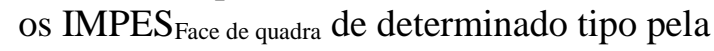
somatória do comprimento de faces de quadra total de um mesmo tipo. A tabela 7 apresenta esses valores agregados por tipo de quadra.

\begin{tabular}{|c|c|c|c|}
\hline \multicolumn{4}{|c|}{ IMPES $_{\text {Tipo de quadra }}$} \\
\hline $\begin{array}{l}\text { Tipo de } \\
\text { quadra }\end{array}$ & $\begin{array}{l}\text { Índice } \\
\text { parcial } \\
\text { Global }\end{array}$ & $\begin{array}{c}\text { Índice } \\
\text { parcial da } \\
\text { Escola I }\end{array}$ & $\begin{array}{c}\text { Classificação } \\
\text { parcial }\end{array}$ \\
\hline IMPES $_{\text {Tipo } 1}$ & 0,985 & 0,433 & regular \\
\hline IMPES $_{\text {Tipo } 2}$ & 1,000 & 0,350 & ruim \\
\hline IMPES $_{\text {Tipo } 3}$ & 1,000 & 0,523 & regular \\
\hline IMPES $_{\text {Tipo } 4}$ & 1,000 & 0,385 & ruim \\
\hline IMPES $_{\text {Tipo } 5}$ & 1,000 & 0,294 & ruim \\
\hline IMPES $_{\text {Tipo } 6}$ & 1,000 & 0,590 & regular \\
\hline IMPES $_{\text {Tipo } 7}$ & 0,923 & 0,595 & regular \\
\hline IMPES $_{\text {Tipo } 8}$ & 0,831 & 0,326 & ruim \\
\hline IMPES $_{\mathrm{G}}$ & $=7,739$ & \multicolumn{2}{|c|}{ IMPES $_{\text {Global = 3,497 (Ruim) }}$} \\
\hline
\end{tabular}

Tabela 7 - Valores dos IMPES Tipo de quadras, IMPES $_{\text {Global max }}$

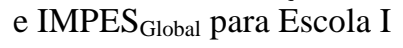

Os dados da tabela 7 mostram que os tipos de quadras que receberam a melhor avaliação do índice parcial foram: em primeiro lugar o tipo 7 (face de quadra com um ponto de ônibus e 1 travessia), seguido do tipo 6 (face de quadra de escola com 1 travessia e travessia escolar) e, por $16^{\circ}$ Ergodesign - Congresso Internacional de Ergonomia e Usabilidade de Interfaces Humano Tecnológica: Produto, Informações Ambientes Construídos e Transporte

$16^{\circ}$ USIHC - Congresso Internacional de Ergonomia e Usabilidade de Interfaces Humano Computador

CINAHPA | 2017 - Congresso Internacional de Ambientes Hipermídia para Aprendizagem.

último o tipo 3 (face de quadra de avenida com 1 travessia). As piores avaliações, em ordem crescente, foram: tipo 5 (face de quadra perpendicular à avenida com 2 travessias - 1 comum e 1 de avenida), seguida do tipo 8 (face de quadra de avenida com 1 travessia e ponto de ônibus) e, por último o tipo 2 (face de quadra comum com 2 travessias - meio de quadra).

Ao se comparar o IMPES $S_{\text {Global }}$ ao IMPES Global máx (calculado por simulação - neste caso entendido como atribuição de valores máximos em cada um dos indicadores) apresentado na tabela 7 observase que o valor calculado para o IMPES Global máx foi de 7,739, ou seja, esse valor representa a adequação do entorno da escola em $100 \%$, portanto o valor de 3,497 da Escola I representa 45,19\% da avaliação máxima possível. Assim, é perceptível que a avaliação da Escola I chegou a quase metade do valor máximo possível de avaliação, demonstrando uma avaliação mediana ou regular.

O passo seguinte consistiu em realizar a ponderação dos valores da soma dos indicadores e do comprimento das faces de quadra, por meio do cálculo do IMPES ${ }_{\text {Ponderado. }}$ A partir destes resultados foi possível elaborar um mapa com a classificação ponderada de todas as faces de quadra deste entorno escolar, na sequência foram identificadas as melhores rotas entre a escola e os pontos de ônibus. A figura 6 apresenta o mapa do entorno escolar com as faces de quadras indicando o grau de microacessibilidade correspondente. A classificação adotada corresponde à gradação de cores, variando de verde escuro (melhor avaliação) até vinho (pior avaliação).
Realização:

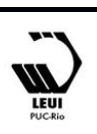




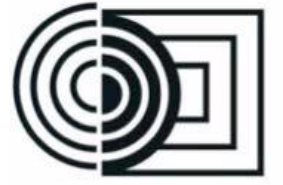
CINAHPA

$16^{\circ}$ Ergodesign - Congresso Internacional de Ergonomia e Usabilidade de Interfaces Humano Tecnológica: Produto, Informações Ambientes Construídos e Transporte

$16^{\circ}$ USIHC - Congresso Internacional de Ergonomia e Usabilidade de Interfaces Humano Computador

CINAHPA | 2017 - Congresso Internacional de Ambientes Hipermídia para Aprendizagem.

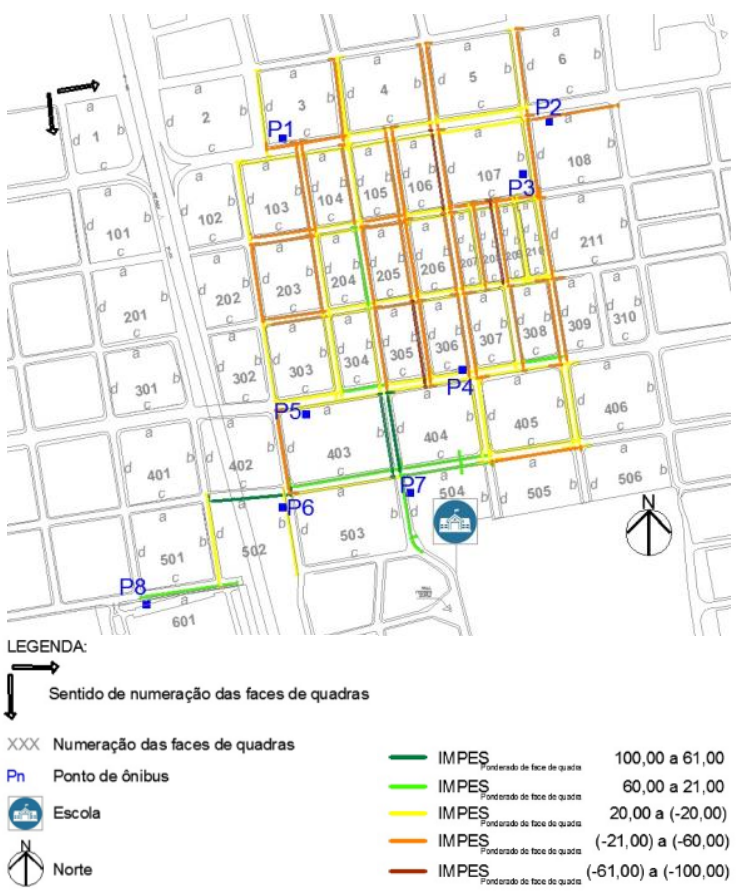

Figura 6 - Mapa do IMPES ponderado por face de quadra da Escola I, sem escala.

De acordo com a figura 6, observa-se que as faces de quadra próximas à Escola I e aos pontos de ônibus P6, P7 e P8 apresentaram as melhores classificações (linhas verde escura e verde clara); e as faces de quadra mais distantes da escola apresentam uma pior classificação (linhas amarela, laranja e vinho). Das 111 faces de quadras analisadas, $9,91 \%$ foram classificadas como Muito favorável ao pedestre ou Favorável ao pedestre; $51,35 \%$ foram classificadas como Parcialmente favorável ao pedestre; e 38,74\% foram classificadas como Desfavorável ou Muito desfavorável ao pedestre.

\section{- Análise das rotas}

Na sequência foram traçadas as melhores rotas a partir de cada ponto de ônibus. No momento do traçado tentou-se priorizar as faces de quadra com melhor avaliação, mesmo que isso representasse maior distância de caminhada.

Dos oito pontos de ônibus existentes, quatro deles (P1, P2, P3, P4) apresentaram 5 rotas favoráveis ou muito favoráveis ao deslocamento do pedestre, dois pontos (P6, P8) apresentaram 2 rotas, um ponto de ônibus (P5) apresentou 3 rotas e outro (P7) apenas uma rota. No total foram identificadas 28 rotas, sendo 9 favoráveis ao pedestre e 19 parcialmente favoráveis aos pedestres para a Escola I.

Os valores do IMPES Ponderado por face de quadra $_{\text {para }}$ classificar as rotas foram calculados por meio da média aritmética das notas de todas as faces de quadra que compõem cada rota. A tabela 8 mostra os valores das médias de cada rota em cada ponto de ônibus analisado na Escola I.

\begin{tabular}{|c|c|c|c|c|c|}
\hline $\begin{array}{l}\text { Rotas/ } \\
\text { Pontos }\end{array}$ & $\begin{array}{c}\mathbf{1}^{\mathbf{a}} \\
\text { ROTA }\end{array}$ & $\begin{array}{c}\mathbf{2}^{\mathbf{a}} \\
\text { ROTA }\end{array}$ & $\begin{array}{c}3^{\mathbf{a}} \\
\text { ROTA }\end{array}$ & $\begin{array}{c}4^{\mathbf{a}} \\
\text { ROTA }\end{array}$ & $\begin{array}{c}5^{\mathbf{a}} \\
\text { ROTA }\end{array}$ \\
\hline P1 & 13,65 & 12,43 & 11,79 & 6,43 & $\begin{array}{l}6,37 \\
\end{array}$ \\
\hline $\mathrm{P} 2$ & 12,08 & 8,04 & 7,43 & 6,68 & 6,33 \\
\hline $\mathrm{P} 3$ & 11,36 & 10,96 & 10,26 & 9,99 & 9,83 \\
\hline P4 & 28,92 & 21,86 & 18,74 & $-10,09$ & $-4,23$ \\
\hline P5 & 36,1 & 35,64 & 13,8 & - & - \\
\hline P6 & 33,94 & 26,37 & - & - & - \\
\hline P7 & 26,69 & & - & - & - \\
\hline P8 & 39,66 & 34,75 & - & - & - \\
\hline \multicolumn{6}{|c|}{ LEGENDA } \\
\hline \multicolumn{2}{|c|}{$\begin{array}{c}1^{\mathrm{a}} \text { MELHOR } \\
\text { ROTA }\end{array}$} & \multicolumn{2}{|c|}{$\begin{array}{c}3^{\mathrm{a}} \text { MELHOR } \\
\text { ROTA }\end{array}$} & \multicolumn{2}{|c|}{$\begin{array}{c}5^{\mathrm{a}} \text { MELHOR } \\
\text { ROTA }\end{array}$} \\
\hline \multicolumn{2}{|c|}{$\begin{array}{c}2^{\mathrm{a}} \text { MELHOR } \\
\text { ROTA }\end{array}$} & \multicolumn{2}{|c|}{$\begin{array}{c}4^{\mathrm{a}} \text { MELHOR } \\
\text { ROTA }\end{array}$} & & \\
\hline
\end{tabular}

Tabela 8 - Médias do IMPES Ponderado por face de quadra $_{\text {para }}$ cada rota

A tabela 8 mostra que as primeiras rotas a partir dos pontos P8, P5, P6, P4 e P7 tem uma média maior que os outros pontos e que as últimas rotas do ponto $\mathrm{P} 4$ chegam a valores extremos negativos devido às faces de quadras que compõem as rotas terem avaliação ruim, também negativa.

Os pontos P5, P6, P7 e P8 apresentaram poucas possibilidades de traçados de rotas, pois à distância entre os respectivos pontos de ônibus e a Escola I são muito curtas, o que diminui as possibilidades de combinações entre faces de quadra para efetivar a rota. No P5 foram três rotas, no P6 e no P8 duas rotas e, no P7 apenas uma rota.

A média geral do IMPES $S_{\text {Ponderado por face de quadra }}$ da Escola I, ou seja, a divisão entre a somatória dos IMPES Ponderado por face de quadra de cada face de quadra
Realização:

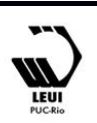




\section{$16^{\circ}$ \\ ERGODESIGN USIHC CINAHPA}

pelas 111 faces de quadra avaliadas nessa escola resultou em -12,09. De acordo com a escala estipulada na tabela 5 da metodologia, a Escola I apresentou resultado final regular, sendo que no mapa geral apresentou algumas faces de quadra ótimas ou boas, a maior parte regular e algumas faces de quadra em situação péssima.

A figura 7 apresentam algumas possibilidades de traçados de rotas a partir do ponto de ônibus P1 até a escola. Neste exemplo foi adotada como simbologia uma escala de intensidade de cores verdes, sendo o verde mais escuro a rota com melhor média seguindo gradativamente até o verde mais claro, sendo esta última a rota com pior média entre as rotas traçadas a partir de um mesmo ponto de ônibus.

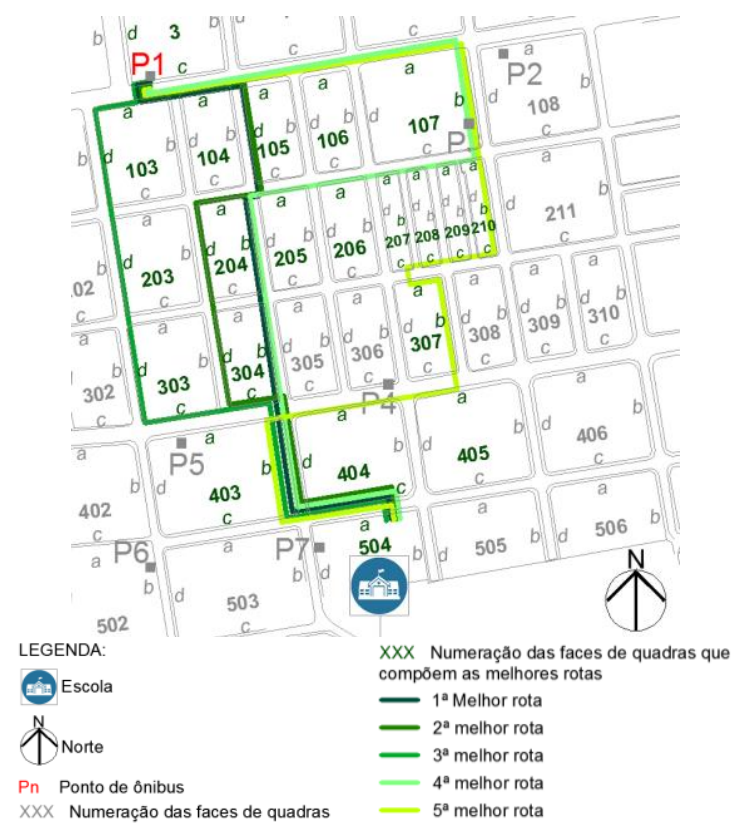

Figura 6 - Rotas acessíveis a partir do ponto P1 (Escola I), sem escala.

A aplicação do instrumento na Escola demonstrou que o índice é adequado para avaliar o grau de microacessibilidade no entorno de áreas escolares, tendo em vista que permitiu que fossem identificados quais indicadores precisam de adequação nesse entorno escolar, além de permitir traçar as melhores rotas entre a escola e os pontos $16^{\circ}$ Ergodesign - Congresso Internacional de Ergonomia e Usabilidade de Interfaces Humano Tecnológica: Produto, Informações Ambientes Construídos e Transporte

$16^{\circ}$ USIHC - Congresso Internacional de Ergonomia e Usabilidade de Interfaces Humano Computador

CINAHPA | 2017 - Congresso Internacional de Ambientes Hipermídia para Aprendizagem.

de ônibus utilizados pelos estudantes.

\section{Considerações Finais}

A aplicação do instrumento possibilita a realização de um diagnóstico geral do entorno escolar, já que os indicadores e as respectivas formas de análise incorporam os principais aspectos que podem contribuir para a utilização do transporte público e do modo a pé para chegar à escola. Permite a identificação do grau de facilidade/dificuldade do deslocamento do pedestre no percurso do ponto de ônibus até a escola.

$\mathrm{O}$ instrumento ainda permite realizar um mapeamento gráfico por meio de ferramentas CAD ou SIG das faces de quadras e das melhores rotas. Os dados obtidos podem ser utilizados por gestores públicos, tanto para realizar diagnóstico como para a implementação de melhoria nos itens que apresentaram avaliação deficitária assegurando acessibilidade, segurança, seguridade, sinalização e conforto aos estudantes no deslocamento em áreas escolares ou, ainda, como suporte para elaboração de planos de rotas que favoreça o deslocamento do pedestre no trajeto para a escola.

\section{BIBLIOGRAFIA}

AGUIAR, F. de O. Acessibilidade Relativa dos Espaços Urbanos para Pedestres com Restrições de Mobilidade. Tese (Doutorado em Transportes)

- Escola de Engenharia de São Carlos,

Universidade de São Paulo, São Carlos, 2010.

ASADI-SHEKARI, Z.; MOEINADDINI, M.;

SHAH, M. Z. Pedestrian safety index for evaluating street facilities in urban areas. Safety science, v. 74, p. 1-14, 2015.

BIANCHI, I. M. A microacessibilidade em vias urbanas estruturais: o caso da $3^{a}$ perimetral de Porto Alegre. Tese (Doutorado) - Programa de Pós-Graduação em Desenvolvimento de Estudos Urbanos e Regionais, Universidade Federal do Rio Grande do Sul, Porto Alegre, 2011.
Realização:

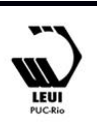




\section{$16^{\circ}$ \\ ERGODESIGN USIHC CINAHPA}

$16^{\circ}$ Ergodesign - Congresso Internacional de Ergonomia e Usabilidade de Interfaces Humano Tecnológica: Produto, Informações Ambientes Construídos e Transporte

$16^{\circ}$ USIHC - Congresso Internacional de Ergonomia e Usabilidade de Interfaces Humano Computador

CINAHPA | 2017 - Congresso Internacional de Ambientes Hipermídia para Aprendizagem.
BRASIL. Lei no 12.587, de 3 de janeiro de 2012 . Institui as diretrizes da Política Nacional de Mobilidade Urbana. Brasília, 2012. Disponível em: <http://www.planalto.gov.br/ccivil_03/_ato20112014/2012/lei/l12587.htm>. Acesso em: 22 set. 2013.

Brasil Acessível. Programa brasileiro de acessibilidade urbana. Cadernos 1, 2, 3, 4, 5 e 6. Secretaria Nacional de Transporte e da Mobilidade Urbana. Brasília, 2007a

PlanMob - Construindo a cidade sustentável. Caderno de referência para Elaboração de Plano de Mobilidade Urbana. SEMOB. Brasília. $2007 b$

CAMPÊLO, A.E.P. Proposição de modelo para escolha de rotas urbanas acessíveis considerando-se os critérios de microacessibilidade para as pessoas com deficiência física motora. Dissertação (Mestrado em Engenharia de Transportes) - Universidade Federal do Ceará, Fortaleza, 2011.

DISCHINGER, M.; BINS ELY; V. H. M.; BORGES, M. M. F.C. Manual de acessibilidade espacial para escolas: $o$ direito à escola acessível. Brasília: Ministérios da Educação, Secretaria de Educação Especial. 2009.

FERREIRA, M. A.; SANCHES, S. P. Proposal of a sidewalk accessibility index. Journal of Urban and Environmental Engineering, v. 1, n. 1, p. 19, 2007.

IPINGBEMI, O. A.; AIWORO, A.B. Journey to school, safety and security of school children in Benin City, Nigeria. Transportation Research, Part F, n. 19: p. 77-84. 2013.

KEPPE JUNIOR, C. L. G. Formulação de um indicador de acessibilidade das calçadas e travessias. Dissertação (Mestrado em Engenharia Urbana). Universidade Federal de São Carlos, São Carlos, 2007.

LITMAN, T.. Traffic, Mobility and Accessibility.
In: Measuring Transportation. Victoria Transport Policy Institute (VTPI). 2008.

MAGAGNIN, R. C.; FONTES, M. S. G. C.; SALCEDO, R. F. B.. Spatial quality evaluation of pedestrian streets. Journal of Civil Engineering and Architecture, v. 8, p. 1574-1584, 2014.

MITCHELL, H.; KEARNS, R. A. \& COLLINS, D. C. A.. Nuances of neighbourhood: Children's perceptions of the space between home and school in Auckland, New Zealand. Geoforum, n. 38: p. 614-627, 2007.

NANYA, L. M.; SANCHES, S. da P. Proposta de instrumento para auditoria e avaliação da caminhabilidade. In: Anais... XXIX Congresso Nacional de Pesquisa em Transporte da ANPET, Ouro Preto, p. 1702-1713, 2015.

Instrumento para auditoria e avaliação da caminhabilidade em áreas escolares. Revistas de Transporte Públicos - ANTP, ano 38, p. 81-94, 2016.

OLIVEIRA, A. M. Um índice para o planejamento de mobilidade com foco em grandes Polos Geradores de Viagens Desenvolvimento e aplicação em um campus universitário. Dissertação (Mestrado) - Escola de Engenharia de São Carlos, Universidade de São Paulo, São Carlos, 2015.

ORLANDI, S. C. Percepção do portador de deficiência física com relação à qualidade dos espaços de circulação urbana. Dissertação (Mestrado em Engenharia Urbana) - Universidade Federal de São Carlos, São Carlos, 2003.

PIANUCCI, M. N.. Análise da acessibilidade do sistema de transporte público urbano: estudo de caso da cidade de São Carlos - SP. Dissertação (Mestrado em Engenharia de Transportes) - Escola de Engenharia de São Carlos, Universidade de São Paulo, São Carlos, 2011.

PRADO, B. B. Instrumento para avaliar a microacessibilidade do pedestre no entorno de
Realização:

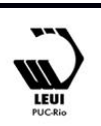




\section{$16^{\circ}$ \\ ERGODESIGN USIHC CINAHPA}

$16^{\circ}$ Ergodesign - Congresso Internacional de Ergonomia e Usabilidade de Interfaces Humano Tecnológica: Produto, Informações Ambientes Construídos e Transporte

$16^{\circ}$ USIHC - Congresso Internacional de Ergonomia e Usabilidade de Interfaces Humano Computador

CINAHPA | 2017 - Congresso Internacional de Ambientes Hipermídia para Aprendizagem.

áreas escolares. 216 p. Dissertação (Mestrado em Arquitetura e Urbanismo) - Faculdade de Arquitetura, Artes e Comunicação, Universidade Estadual Paulista, Bauru, 2016.

PRADO, B.B.; MAGAGNIN, R. C. Fatores que podem afetar a escolha de rotas seguras no trajeto por caminhada entre o ponto de ônibus e a escola. In: Maria Solange Gurgel de Castro Fontes, Obede Borges Faria e Rosio Fernández Baca Salcedo. (Org.). Pesquisa em arquitetura e urbanismo: Fundamentação teórica e métodos. 1ed. Bauru: Cultura Acadêmica, 2016, v. 1, p. 165-186.

RODRIGUES, M. A.; SORRATINI, J. A.. A qualidade no transporte coletivo urbano. In: Anais... Congresso de Pesquisa e Ensino em Transportes - ANPET. V. 22, p. 1081-1092, 2008.

SILVEIRA, C. S. Acessibilidade Espacial no Transporte Público Urbano: Estudo de Caso em Joinville-SC. Dissertação (Mestrado em

Arquitetura e Urbanismo). Universidade Federal de Santa Catarina, Florianópolis, 2012.

VAN EGGERMOND, M. A.B.; ERATH, A. Accessibility on a micro-level: a closer look at pedestrian routing and network generation. Proceedings of the Eastern Asia Society for Transportation Studies, v.9, 2013.

VASCONCELLOS, E. A. Mobilidade urbana e cidadania. Rio de Janeiro: SENAC Nacional Editora, 2012.

ZALY SHAH, M.; RODRIGUES DA SILVA, A. N. Pedestrian Infrastructure and Sustainable Mobility in Developing Countries: The Cases of Brazil and Malaysia. In: Anais... XVI Panam Conference Proceeding, Lisbon, Portugal. 2010. 